Article

\title{
Increasing Growth of Lettuce and Mizuna under Sole-Source LED Lighting Using Longer Photoperiods with the Same Daily Light Integral
}

\author{
Shane Palmer(D) and Marc W. van Iersel * (1) \\ Department of Horticulture, University of Georgia, Athens, GA 30602, USA; palmersbio@gmail.com \\ * Correspondence: mvanier@uga.edu
}

Received: 9 October 2020; Accepted: 24 October 2020; Published: 28 October 2020

\begin{abstract}
Light recommendations for horticultural crops often focus on the optimal daily light integral (DLI) without regard to how that light is delivered throughout each day. Because photosynthesis is more efficient at lower photosynthetic photon flux density (PPFD), we hypothesized that longer photoperiods with lower PPFD results in faster growth than shorter photoperiods with higher PPFD and the same DLI. We quantified the effect of different photoperiods, all providing the same DLI, on photosynthesis and growth of two leafy greens. Mizuna (Brassica rapa var. japonica) and lettuce (Lactuca sativa) "Little Gem" were grown from seed in a controlled environment chamber $\left(20^{\circ} \mathrm{C}\right.$ and $\left.819 \mu \mathrm{mol} \cdot \mathrm{mol}^{-1} \mathrm{CO}_{2}\right)$ under six photoperiods $(10,12,14,16,18$, and $20 \mathrm{~h})$. LED fixtures provided white light and PPFD was adjusted so each treatment received a DLI of $16 \mathrm{~mol} \cdot \mathrm{m}^{-2} \cdot \mathrm{d}^{-1}$. Mizuna and lettuce were harvested 30 and 41 days after planting, respectively. Longer photoperiods with lower PPFD increased light interception, chlorophyll content index, quantum yield of photosystem II, and aboveground biomass, but decreased instantaneous $\mathrm{CO}_{2}$ assimilation of lettuce and mizuna. Aboveground biomass increased $16.0 \%$ in lettuce and $18.7 \%$ in mizuna in response to increasing the photoperiod from 10 to $20 \mathrm{~h}$. In summary, extending the photoperiod and lowering PPFD increases growth of lettuce and mizuna by increasing light interception and the quantum yield of photosystem II.
\end{abstract}

Keywords: Brassica rapa var. japonica; Lactuca sativa; light-emitting diodes; leafy greens; light interception; photosynthesis; plant factory

\section{Introduction}

Photosynthesis is the primary process plants use to accumulate biomass, and whole-plant photosynthesis is directly related to overall crop productivity [1,2]. In controlled environment agriculture, such as greenhouses and plant factories, natural sunlight is supplemented or replaced with electrical lighting to achieve adequate photosynthesis and growth. The cost of electricity in such facilities is high, comprising up to $30 \%$ of growers' operating costs [3]. With the advent of dimmable light-emitting diode (LED) lighting fixtures and programmable control systems, the timing and intensity of horticultural lighting can be controlled more precisely than ever before.

Light recommendations for crops often focus on the optimal daily light integral (DLI, total amount of photosynthetic light received by a plant in a day), without regard to how that light is delivered over time [4]. The daily light integral is a function of the photoperiod and photosynthetic photon flux densities (PPFDs) throughout that photoperiod. Finding the optimal way to provide supplemental or sole-source lighting, maximizing the efficiency with which plants intercept and use light to produce marketable biomass, has the potential to reduce input costs and increase yields and profitability [5]. Plants use light most efficiently for photosynthesis at lower light intensities [6], 
suggesting that providing a specific DLI over longer photoperiods and lower PPFDs increase daily photosynthesis and potentially growth. Such lighting approaches have been studied since at least the 1970s. Early studies on different crops (sugar beet, beetroot, and spinach beet (Beta vulgaris ssp. vulgaris), lettuce (Lactuca sativa), cabbage (Brassica oleracea), oilseed rape (B. napus ssp. napus), radish (Raphanus sativus), celery (Apium graveolens), and tomato (Solanum lycopersicum)) demonstrated that when the same total amount of light is delivered to plants at a lower intensity across a longer photoperiod, plants produced more biomass. This was attributed to greater net assimilation [7-10]. In some of these studies, the photoperiod was extended with very low-intensity light at the beginning and/or end of the photoperiod, which adds a negligible amount of light to the total DLI $[7,8]$. However, this approach may introduce confounding effects, caused by shade responses induced by that low-intensity light, especially if that light is provided by incandescent bulbs, which have a low red:far-red ratio. In addition, some prior studies used different combinations of multiple lamp types (e.g., fluorescent and incandescent bulbs) to achieve their desired light levels, which introduced differences in light spectra among treatments [7,8]. In another study [9], the type of lights used or how the different light intensities in each photoperiod treatment were achieved were not reported.

More recently, growth and photosynthesis of tomato plants under $12 \mathrm{~h}$ and $24 \mathrm{~h}$ photoperiods with the same DLI were compared, in part to investigate whether diurnal temperature fluctuations could mitigate injury caused by continuous lighting [10]. Despite many plants developing physiological injuries from the $24 \mathrm{~h}$ photoperiod treatment, they still produced more biomass than plants grown in the $12 \mathrm{~h}$ photoperiod treatment. Taking advantage of dimmable LED fixtures, we previously conducted greenhouse trials where plants in different treatments all received the same DLI, but spread out over photoperiods ranging from 12 to $21 \mathrm{~h}$. The shoot and root dry mass of Rudbeckia fulgida var. sullivantii seedlings increased by 30 and $24 \%$, respectively, as the photoperiod increased from 12 to $21 \mathrm{~h} \mathrm{[11],}$ while lettuce shoot dry mass increased by $28 \%$ [12]. Under sole-source lighting, the effect of longer photoperiods, with the same DLI, on the growth of lettuce may be greater when that DLI is higher [13], consistent with the finding that the total daily electron transport rate through photosystem II responds more strongly to longer photoperiods when the DLI is higher [14].

Crop growth depends on how much light is intercepted by the crop and how efficiently that light is subsequently used for biomass production. Thus, our goal was to quantify the effects of different photoperiod and PPFD combinations on light interception and photosynthetic physiology of two species of leafy greens (lettuce and mizuna (Brassica rapa var. japonica)). We hypothesized that longer photoperiods with lower PPFD increase photosynthetic efficiency, resulting in faster growth than shorter photoperiods with higher PPFD.

\section{Materials and Methods}

\subsection{Growing Space Setup and Lighting Treatments}

The experiment was conducted in a walk-in growth chamber (temperature $19.1 \pm 0.4{ }^{\circ} \mathrm{C}$; vapor pressure deficit $1.38 \pm 0.15 \mathrm{kPa} ; \mathrm{CO}_{2}$ concentration $819 \pm 43 \mu \mathrm{mol} \cdot \mathrm{mol}^{-1}$; means $\pm \mathrm{SD}$ ). Three metal racks were housed within the growth chamber. Each rack contained three shelves, which were divided into two sections to create six individual growing areas per rack; the three racks together contained a total of 18 growing areas. Small fans were mounted at evenly spaced intervals along the edges of the racks within each growing area to provide horizontal air flow over the canopy. Two LED light bars (SPYDRx Plus with PhysioSpec indoor spectrum; Fluence Bioengineering, Austin, TX, USA) supplied light to each growing area. One dimmable driver controlled three pairs of lights, one pair on each rack. Six drivers allowed for six different lighting treatments in each rack. Each full rack represented one block, for a total of three blocks. Treatment positions were randomized within each rack. The experiment was replicated twice in the same growth chamber and treatments were re-randomized for the second experiment. 
Plants were grown under six photoperiods $(10,12,14,16,18$, and $20 \mathrm{~h})$. The PPFD output from the light fixtures in each treatment was adjusted so that all treatments received the same DLI of $16 \mathrm{~mol} \cdot \mathrm{m}^{-2} \cdot \mathrm{d}^{-1}$ throughout the study (Table 1$)$. The PPFD output was adjusted using pulse width modulation (PWM) signals from a datalogger (CR6; Campbell Scientific, Logan, UT, USA) to the drivers. The PPFD was measured at the substrate surface under each light fixture using a handheld quantum sensor (SS-110; Apogee Instruments, Logan, UT, USA).

Table 1. The six lighting treatments with different photoperiods and photosynthetic photon flux density (PPFD). The PPFD decreased proportionally as the photoperiod increased to maintain a daily light integral (DLI) of $16 \mathrm{~mol} \cdot \mathrm{m}^{-2} \cdot \mathrm{d}^{-1}$ in all treatments.

\begin{tabular}{|c|c|}
\hline Photoperiod (h) & PPFD $\left(\mu \mathrm{mol} \cdot \mathrm{m}^{-2} \cdot \mathrm{s}^{-1}\right)$ \\
\hline 10 & 444 \\
\hline 12 & 370 \\
\hline 14 & 318 \\
\hline 16 & 278 \\
\hline 18 & 247 \\
\hline 20 & 222 \\
\hline
\end{tabular}

\subsection{Plant Material and Growing Practices}

Mizuna and lettuce "Little Gem" were grown from seed. Seeds were sown in $10 \mathrm{~cm}$ square plastic pots containing soilless substrate (Fafard 3B mix; Sun Gro Horticulture, Agawam, MA, USA) and the trays were subirrigated daily using an automated ebb-and-flow system supplying a fertilizer solution containing $100 \mathrm{mg} \cdot \mathrm{L}^{-1}$ total N (15N-2.2P-12.5K, Peters Excel 15-5-15 Cal-Mag Special, ICL Specialty Fertilizers, Dublin, OH, USA). Fertilizer solution was added to the ebb-and-flow reservoirs as needed; the solution in the reservoirs was not changed during the experiment. One tray with 15 pots of each of the two species was placed in each growing area. Species were arranged randomly within each section, and re-randomized in each experiment.

The mizuna and lettuce grew at different rates and were harvested at 30 and $41 \mathrm{~d}$ after planting (DAP), respectively. Harvest times were determined by visual inspection; mizuna plants were harvested when they outgrew the available space, while the lettuce was harvested when most of the plants had reached a commercial size.

\subsection{Data Collection}

Leaf chlorophyll content index (CCI, a dimensionless indicator of leaf chlorophyll content) was measured with a handheld chlorophyll content meter (CCM-200 plus; Opti-Sciences, Hudson, NH, USA) in both species at regular intervals during both experiments. Four fully expanded leaves in each tray were measured and the average CCI value calculated.

The quantum yield of photosystem II was measured with a chlorophyll fluorometer (Mini-PAM; Walz, Effeltrich, Germany) on leaves of both species just before harvest (29 and 40 DAP for mizuna and lettuce, respectively) during the first experiment. Four fully expanded leaves with direct exposure to the overhead lights were measured in each experimental unit and the average of the four readings in each unit was calculated.

Photosynthesis-light response curves were measured with a portable leaf photosynthesis system (CIRAS-3; PP Systems, Amesbury, MA, USA) shortly before final harvest in the second experiment; mizuna was measured between 25 and 28 DAP, and lettuce was measured between 38 and 41 DAP. Light response curves were measured on one leaf of one representative plant from each experimental unit, for a total of 18 curves per species. Net photosynthesis was measured under eleven PPFDs, ranging from 0-2000 $\mu \mathrm{mol} \mathrm{m} \mathrm{m}^{-2} \mathrm{~s}^{-1}$, administered from lowest to highest intensity. Each PPFD level was maintained for $180 \mathrm{~s}$. Light was provided by white LEDs built into the leaf cuvette. Leaf temperature and $\mathrm{CO}_{2}$ concentration in the cuvette were maintained at $25^{\circ} \mathrm{C}$ and $800 \mu \mathrm{mol} \cdot \mathrm{mol}^{-1}$, respectively. 
Canopy light interception of both species was measured at regular intervals throughout both experiments using a ceptometer (AccuPAR LP-80; Meter Group, Pullman, WA, USA). The ceptometer light sensor bar was inserted below the canopy at the pot level in four different directions and the average light level of the four measurements was calculated. Light interception percentage was determined by using an initial light measurement at the top of each tray before seedlings emerged as the reference value $(0 \%$ light interception) for subsequent measurements. Light interception percentage was calculated as ((initial light level—current level)/initial light level) $\times 100 \%$.

Leaf area and aboveground biomass were measured in both experiments. Leaves were separated and counted during harvest and total leaf area was measured with a leaf area meter (LI-3100; Lincoln, $\mathrm{NE}, \mathrm{USA}$ ). Aboveground dry mass was measured after drying the samples in a drying oven at $80{ }^{\circ} \mathrm{C}$ for approximately $72 \mathrm{~h}$. Biomass of root/hypocotyl tissue from mizuna plants was also measured during the second experiment.

\subsection{Experimental Design and Data Analysis}

The experiment used a randomized complete block design with three blocks, and it was replicated twice in time. Most data were analyzed using mixed models (JMP statistical software, SAS Institute, Cary, NC, USA).

Light response curves were fitted in SigmaPlot (Version 11.0, Systat Software, Inc., San Jose, CA, USA) using a three-parameter exponential rise to a maximum with the equation:

$$
P_{n}=R_{d}+P_{g, \max } \times\left(1-e^{-Q Y m \times P P F D / P g, m a x}\right),
$$

where $P_{n}$ is net photosynthesis, $R_{d}$ is dark respiration, $P_{g, \max }$ is the light-saturated gross photosynthesis, and $Q Y_{m}$ is the maximum quantum yield of $\mathrm{CO}_{2}$ fixation ( $\mathrm{mol}$ of $\mathrm{C}$ fixed/mol of incident light; the initial slope of the regression curve). These three physiological parameters were analyzed as a function of PPFD. The light response curves were also used to estimate the leaf $P_{n}$ at the PPFD the plants were grown under. Parameters from these regressions were analyzed with the same mixed model method as the other data.

The data were analyzed using mixed models (JMP, Sas Institute, Cary, NC, USA). Aboveground biomass data from both species and both experiments were pooled together for analysis; experimental replicate and block were random effects while photoperiod or PPFD, species, and species $\times$ photoperiod (or PPFD) interaction were fixed effects.

\section{Results and Discussion}

\subsection{Leaf Characteristics and Light Interception}

There was no difference in final leaf area or area per leaf among photoperiod treatments in either lettuce or mizuna. However, differences in canopy light interception arose over time and these differences persisted until harvest. Both species had greater light interception with longer photoperiods. During the first experiment, differences occurred in lettuce starting at 26 DAP and in mizuna at 18 DAP (Figure 1). This pattern was similar in the second experiment, where differences occurred in lettuce and mizuna starting at 25 and $23 \mathrm{DAP}$, respectively (data not shown).

Since there was no difference in total leaf area or area per leaf among photoperiod treatments, other morphological factors must account for the differences in light interception percentage. Under lower PPFD, plants may have had longer leaves that extended farther to increase light interception; We have previously seen that lettuce plants grown under lower PPFD had longer leaves than those grown under higher PPFD, which reduced overlap of leaves and increased light interception (Legendre, pers. comm.). In an experiment comparing Iris pumila plants grown in shaded versus unshaded natural habitats (estimated average PPFD of 55 and $505 \mu \mathrm{mol} \mathrm{m}{ }^{-2} \mathrm{~s}^{-1}$, respectively), leaf length, leaf width, and leaf area were all higher in shaded plants, but the magnitude of the increase 
in leaf length was greater than that of the leaf width [15]. This indicates that shade may induce a change in leaf shape that reduces intra-plant shading and increases light interception.

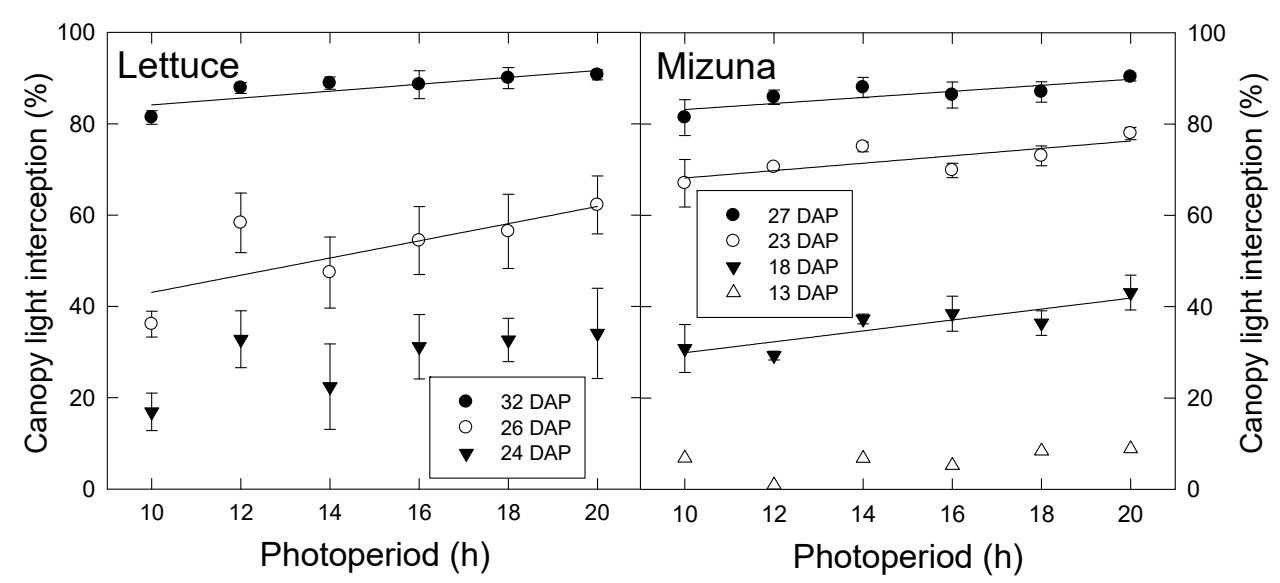

Figure 1. Canopy light interception of lettuce (left) and mizuna (right) grown with varying photoperiods with the same daily light integral of $16 \mathrm{~mol} \cdot \mathrm{m}^{-2} \cdot \mathrm{d}^{-1}$. Data were collected during the first experiment on different days after planting (DAP). Lines indicate significant linear effects of photoperiod $(p<0.05)$.

In addition to possible changes in leaf shape causing differences in light interception, lettuce plants grown under the shortest photoperiod with the highest PPFD had leaves held at a steeper angle toward the light source than those of plants grown under longer photoperiods (Figure 2), which reduces light exposure. Visual differences in lettuce leaf angle decreased as the plants aged. Lettuce plants in the shortest photoperiod treatment also had lighter green leaves (consistent with lower chlorophyll content) than those in the longest photoperiod treatment.

Lettuce and mizuna both had higher leaf chlorophyll content index (CCI) under longer photoperiod treatments in both experiments. CCI increased over time in both species during the second experiment, but this did not occur during the first experiment (Figure 3; only data from experiment 2 shown). During the first experiment, photoperiod effects on CCI of lettuce and mizuna were no longer significant at 41 and $27 \mathrm{DAP}$, respectively, but photoperiod effects on CCI remained significant throughout the second study. We previously hypothesized that the increase in CCI in the longer photoperiod/lower PPFD treatments is a shade-acclimation response to increased leaf light absorption under low PPFD [12]. However, in subsequent studies, we have observed that CCI increases with increasing PPFD, if all plants are exposed to the same photoperiod (unpublished results). This suggests that the observed treatment effects are the result of differences in photoperiod, rather than PPFD. Since chlorophyll production is a light-regulated process [16], the shorter photoperiods may simply reduce the amount of time during which the plants can produce chlorophyll.

Many of the lettuce plants developed tip burn during the latter part of the experiment (Figure 2C). The frequency of tip burn occurrence was not measured; however, it was present in plants from all six photoperiod treatments. Tip burn in lettuce is a physiological disorder attributed to localized calcium deficiency in fast-growing leaf tissues; the most likely cause of this condition was inadequate air circulation near the meristems of the plants [17]. The fans installed on the growth racks provided horizonal air flow above the lettuce canopy, but may not have been sufficient to penetrate the tightly packed center leaves of the rosettes. In a greenhouse study using an adaptive supplemental lighting system to provide different photoperiods with the same DLI, tip burn in "Little Gem" lettuce was more common in plants grown under longer photoperiod treatments, consistent with the faster growth of those plants [12]. Calcium deficiency tends to be exacerbated in faster-growing plants [18]. 


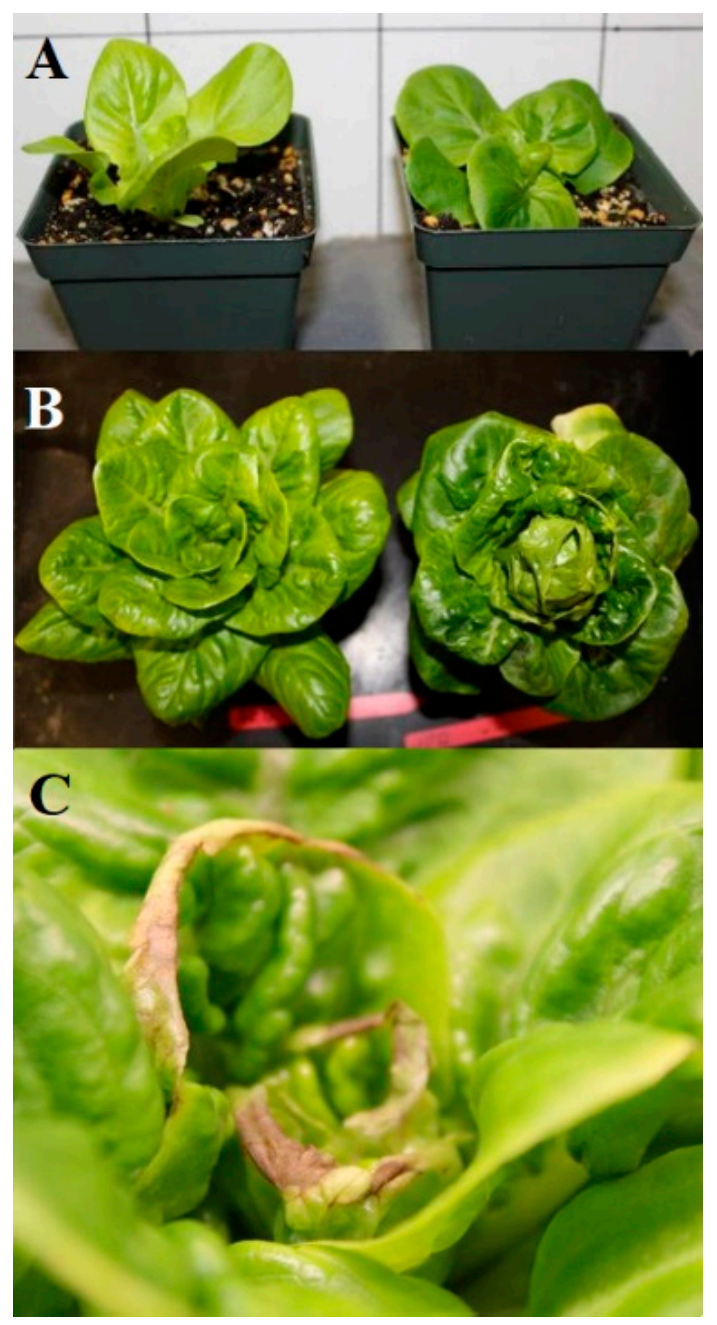

Figure 2. Pictures of lettuce grown in second experiment. Visual appearance of lettuce plants grown under $10 \mathrm{~h}$ (left) and $20 \mathrm{~h}$ (right) photoperiods with the same daily light integral of $16 \mathrm{~mol} \cdot \mathrm{m}^{-2} \cdot \mathrm{d}^{-1}$ at (A) 21 and (B) 41 days after planting; (C) tip burn on inner leaves of lettuce plant.

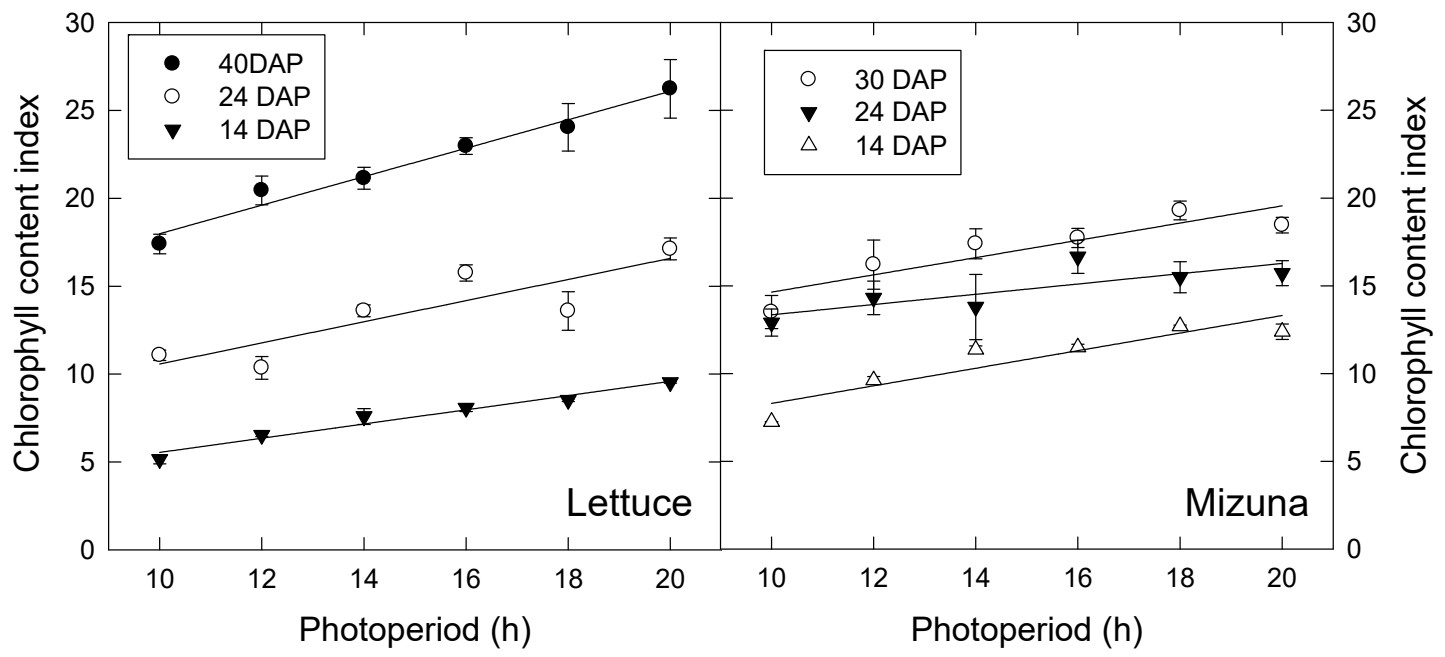

Figure 3. Chlorophyll content index of lettuce (left) and mizuna (right) grown under varying photoperiods with the same daily light integral of $16 \mathrm{~mol} \cdot \mathrm{m}^{-2} \cdot \mathrm{d}^{-1}$. Data shown were collected during the second experiment and on different days after planting (DAP). Data points represent the mean $\pm \mathrm{SE}$ $(n=3)$. Lines indicate significant linear effects of photoperiod $(p<0.05)$. 


\subsection{Leaf Photosynthesis}

Lettuce and mizuna both had higher $\Phi_{\mathrm{PSII}}$ when grown under longer photoperiod treatments with lower PPFD ( $p=0.0023$ and $p<0.0001$, respectively) (Figure 4); doubling the PPFD from 222 to 444 resulted in $9 \%$ and $11 \%$ decreases in $\Phi_{\mathrm{PSII}}$ in lettuce and mizuna, respectively. These results are consistent with prior research demonstrating that photochemistry is more efficient at lower light intensities [6,19]. At high PPFD, a larger proportion of the PSII reaction centers are closed, making them incapable of accepting additional excitation energy from photons. In addition, heat dissipation of absorbed light energy is upregulated in response to higher PPFD [20]; thus, a larger proportion of the absorbed photons are not used for photosynthesis, but instead their excitation energy is dissipated as heat or re-emitted as fluorescence light to avoid damaging the PSII machinery [20]. We have previously found that $\Phi_{\mathrm{PSII}}$ of lettuce varies little during different photoperiods with constant PPFD, resulting in greater daily electron transport through photosystem II under longer photoperiods with lower PPFD [14]. We did not calculate electron transport rates in the current study, because leaf absorptance values are needed to do so. We did not measure leaf absorptance, but it likely differed among treatments. Leaf absorptance is correlated with leaf chlorophyll levels [21] and the leaves of plants grown under longer photoperiods, and with higher CCI, thus likely had higher leaf absorptance.

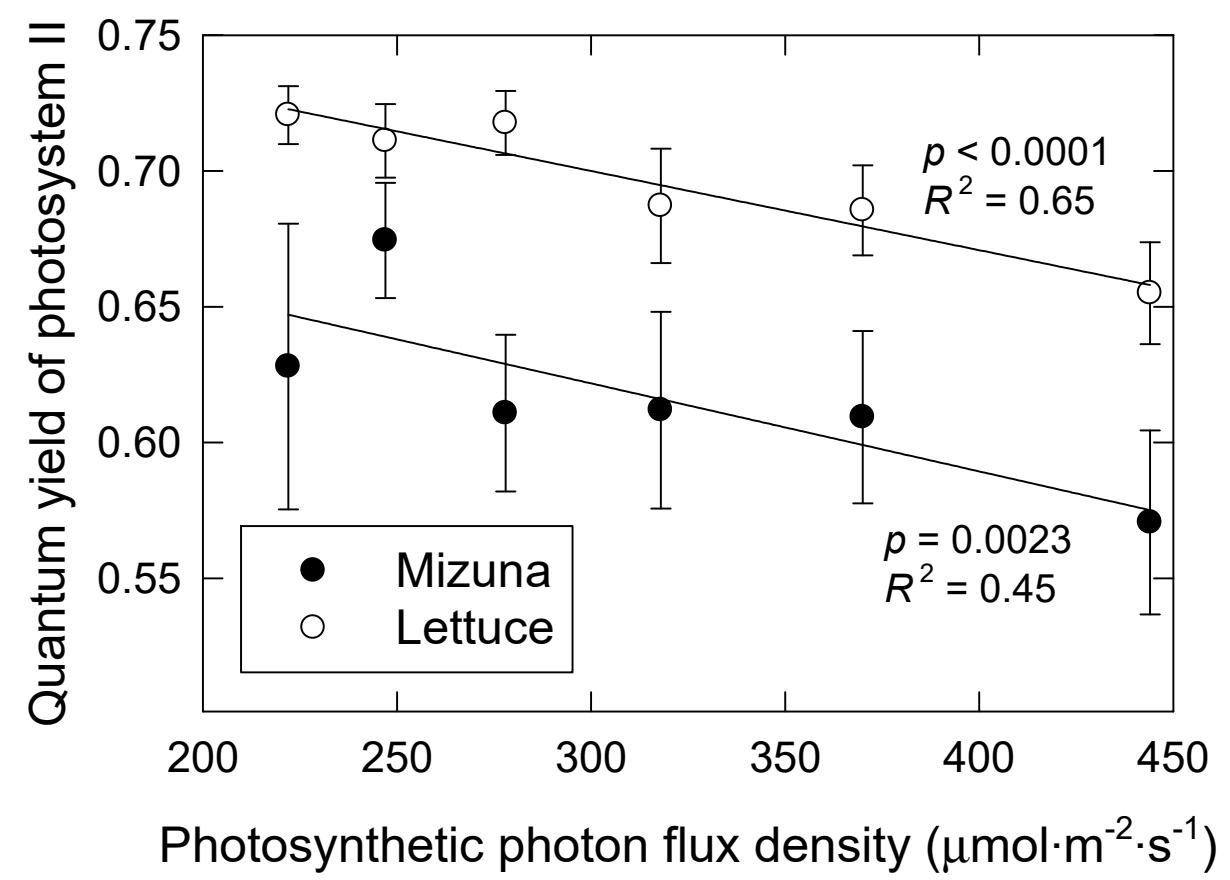

Figure 4. Quantum yield of photosystem II of lettuce and mizuna, grown under varying photosynthetic photon flux densities with different photoperiods, result in the same daily light integral $\left(16 \mathrm{~mol} \cdot \mathrm{m}^{-2} \cdot \mathrm{d}^{-1}\right)$. Data were collected during the first experiment. Data points represent the mean \pm SE $(n=3)$. Lines indicate significant linear effects $(p<0.05)$.

Dark respiration did not differ among photoperiod treatments in either species and averaged 3.4 and $4.5 \mu \mathrm{mol} \mathrm{m} \mathrm{m}^{-2} \mathrm{~s}^{-1}$ for lettuce and mizuna, respectively. The maximum quantum yield of $\mathrm{CO}_{2}$ fixation also did not differ among photoperiod treatments in either species and averaged 0.066 and $0.070 \mathrm{~mol} \mathrm{~mol}^{-1}$ for lettuce and mizuna, respectively. $P_{g, \max }$ of lettuce decreased from 44.2 to $33.6 \mu \mathrm{mol} \cdot \mathrm{m}^{-2} \cdot \mathrm{s}^{-1}$ as PPFD increased $(p=0.01)$, but there was no effect in mizuna (average $\mathrm{P}_{\mathrm{g} \text {,max }}$ of $44.5 \mu \mathrm{mol} \cdot \mathrm{m}^{-2} \cdot \mathrm{s}^{-1}$ ) (Figure 5). The decrease in lettuce $\mathrm{P}_{\mathrm{g} \text {,max }}$ under high light follows a similar trend as CCI and lettuce $\mathrm{P}_{\mathrm{g} \text {,max }}$ and CCI were positively, but not strongly, correlated $\left(p=0.022, R^{2}=0.30\right)$. Similar responses occurred in three species of Heliconia under high light conditions; plants exhibited lower quantum yield, had a lower maximum photosynthetic rate, and lower chlorophyll content per unit leaf area when grown in full sun, compared with those grown under varying shade levels [22]. 


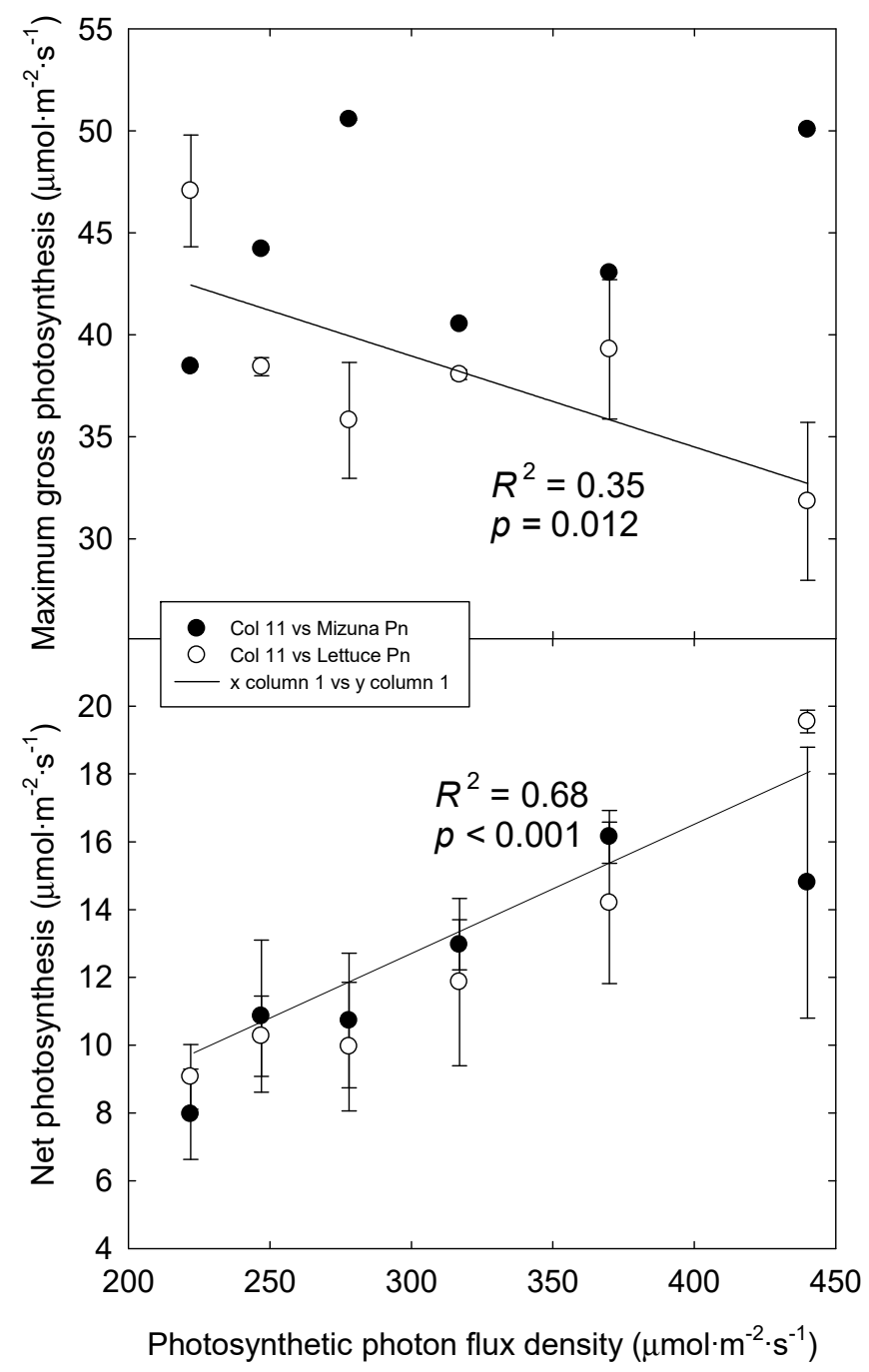

Figure 5. Light-saturated maximum gross photosynthesis $\left(\mathrm{P}_{\mathrm{g}, \max }\right)$ of lettuce and mizuna grown under varying photoperiods and photosynthetic photon flux densities (PPFDs) with the same daily light integral of $16 \mathrm{~mol} \cdot \mathrm{m}^{-2} \cdot \mathrm{d}^{-1}$ (top) and actual net photosynthesis at the PPFD the plants were grown at (bottom). Data were collected from the second experiment. Data points represent the mean $\pm \mathrm{SE}$ $(n=3)$. Lines indicates effects of PPFD on the $P_{g, \max }$ of lettuce (top) and the actual photosynthesis of lettuce and mizuna combined (bottom).

\subsection{Biomass Production}

Averaged over both experiments, both lettuce and mizuna grown under longer photoperiods with lower PPFD had greater aboveground biomass ( $16.0 \%$ and $18.7 \%$ increases, respectively) than those grown under shorter photoperiods with higher PPFD $(p<0.0001)$. Longer photoperiods also resulted in $42 \%$ greater tuber biomass in mizuna $(p=0.022)$ (Figure 6$)$, although total biomass of tubers was low and the fraction of total biomass allocated to tubers was not affected by photoperiod $(\sim 4.3 \%$ of total biomass).

While mizuna is not grown as a tuber crop, it can be utilized as a as a "cut and come again" crop with repeat harvesting [23,24], so its tubers may act as an important stored energy source for leaf regeneration. This ability to form tubers may be detrimental for the crop that is harvested only once, if a large amount of photosynthates are allocated to tuber growth rather than shoot biomass. Since tuber biomass accounted for only $\sim 4.3 \%$ of total biomass, however, it is unclear whether significant gains in aboveground biomass could be made by inhibiting tuber formation. Although not a topic of our study, we did observe the formation of new leaves from the tubers after the shoots had been harvested. 


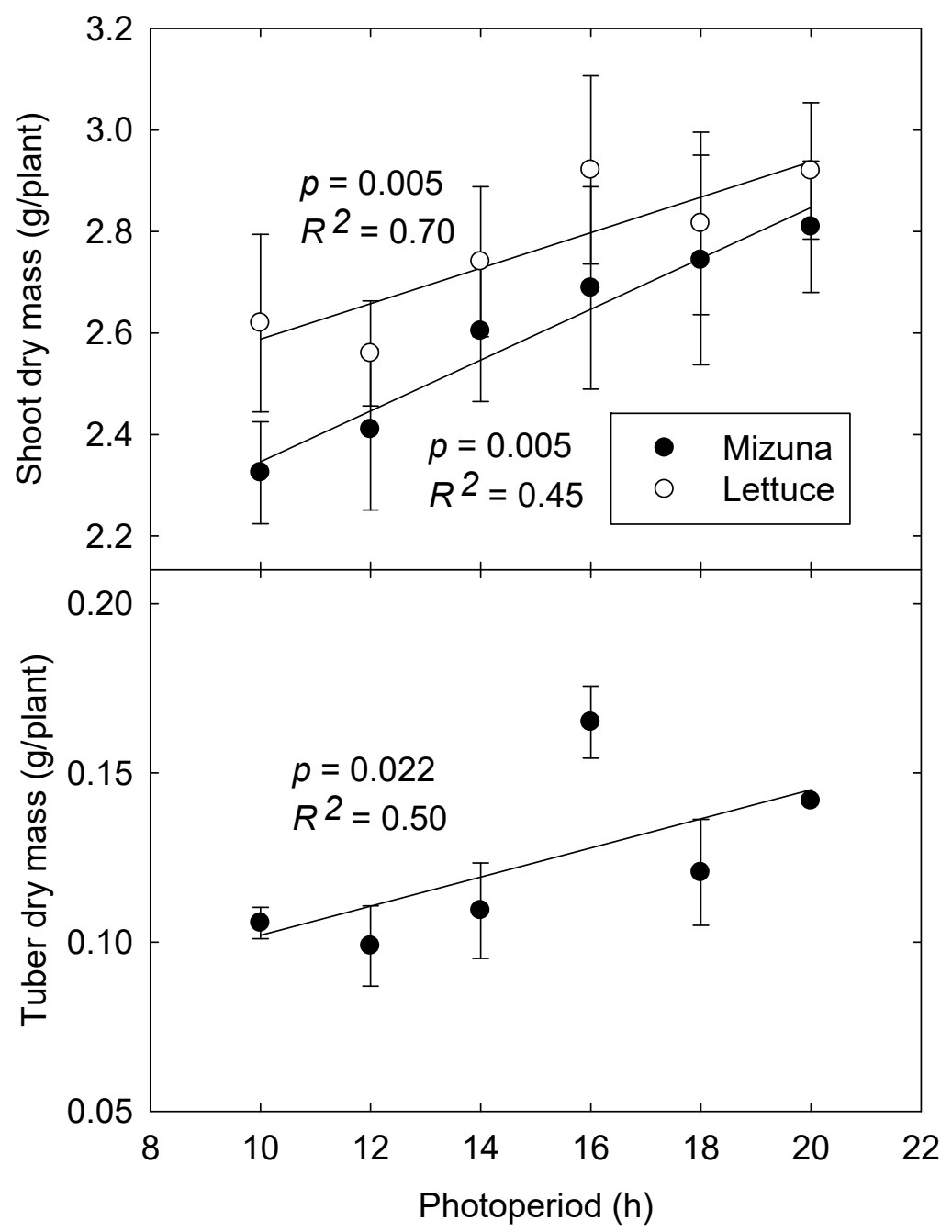

Figure 6. Aboveground biomass of lettuce and mizuna (top) and tuber biomass of mizuna (bottom, data from 2nd study only) grown under different photoperiods and photosynthetic photon flux densities with the same daily light integral of $16 \mathrm{~mol} \cdot \mathrm{m}^{-2} \cdot \mathrm{d}^{-1}$. Error bars represent SE (shoot dry mass: $n=6$; tuber dry mass: $n=3$ ).

\subsection{Lighting Treatments and Yield Potential}

Crop yields can be described using a simple equation [25]:

Yield $=($ total incident PPFD over the growing season $) \times($ PPFD interception efficiency $)$ $\times($ PPFD conversion efficiency) $\times$ (harvest index $)$

To maximize yields, the different components of this equation need to be maximized, while considering that maximizing yield does not necessarily optimize economic returns. For example, increasing the total incident PPFD over the growing season can be increased by either increasing PPFD or extending the crop production cycle. However, increasing the PPFD also increases both capital expenses, due to the need for more or higher power light fixtures, and operating expenses, because of the increased electricity use. Thus, increasing total incident PPFD may not be economically feasible.

Increasing PPFD interception efficiency can also be achieved in multiple ways. A high plant density allows seedlings to quickly develop a large canopy, allowing them to intercept much of the provided light [26]. For example, increasing the planting density of sowthistle (Ixeris dentata Nakai) had little effect on fresh and dry weight per plant, but increased the fresh and dry weight per unit growing area [27]. Light interception also can be increased through lighting treatments. In 
the current study, we found that longer photoperiods with lower PPFD increase the fraction of the provided light that is intercepted by the canopy. Light spectrum also can be used to modify the canopy architecture and, in particular, the use of far-red light has received much attention in recent years. Far-red light induces shade responses in many crops [28,29], and can increase leaf expansion and crop growth [30]. Finally, high chlorophyll levels can increase leaf absorptance [21] and thus canopy light interception. Although leaf chlorophyll levels are strongly affected by fertilization, our results suggest that lengthening the photoperiod can also increase leaf chlorophyll content.

The PPFD conversion efficiency is a complex term that incorporates much of the physiological process that drives growth (see [31] for an in-depth review). The first step in this process is the use of absorbed photons to drive electron transport in the light reactions of photosynthesis. The $\Phi_{\mathrm{PSII}}$ inevitably decreases while electron transport rate increases with increasing PPFD (Figure 4) [6,14,32]. Therefore, maximizing $\Phi_{\text {PSII }}$ is not feasible, since it will unavoidably result in low electron transport rates and low photosynthetic rates. However, there may be opportunities to breed for cultivars with a higher $\Phi_{\text {PSII }}[14]$, which may increase growth and the overall resource use efficiency in plant factories.

The ATP and NADPH produced in the light reactions of photosynthesis are subsequently used in the Calvin cycle to produce carbohydrates. $\mathrm{CO}_{2}$ enrichment can increase crop productivity by providing more substrate to Rubisco, the key enzyme in the Calvin cycle, while at the same time suppressing Rubisco's oxygenation reactions. However, Rubisco activity can still be a limiting step in crop production, because it is a large enzyme, thus requiring much nitrogen [33], with a low catalytic rate [34]. The Rubisco in C3 plants does not have the optimal catalytic properties for plants grown under elevated $\mathrm{CO}_{2}[35]$ and there is much interest in improving Rubisco properties [34,36].

The carbohydrates produced in the Calvin cycle subsequently are used to support respiration and produce biomass. The carbon use efficiency (the fraction of fixed carbon incorporated into biomass) is a function of the relative growth rate of the crop [37]. Lighting conditions thus need to support sustained high crop growth rates, or a large fraction of the produced carbohydrates will be lost through respiration.

Finally, a high harvest index, the edible biomass as a fraction of total biomass, needs to be high to achieve a high marketable yield. Leafy greens have a high harvest index [38], so it is not likely that this can be much increased.

\section{Conclusions}

The observed increases in biomass in response to longer photoperiods likely occurred because of a combination of morphological and physiological responses. Lower PPFDs combined with

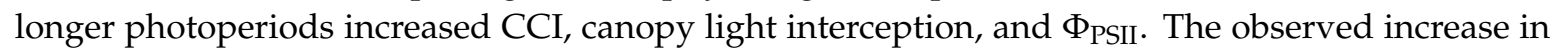
growth under lower PPFDs and longer photoperiods is consistent with prior studies, which found that when DLI is held constant, plants generally produce more biomass when grown under longer photoperiods $[7-9,11,12,39,40]$. The observation that spreading a given DLI over a longer photoperiod with a lower instantaneous PPFD has clear benefits to growers; first, the initial capital expenses can be reduced because fewer lighting fixtures are needed to provide the lower PPFD. Second, by improving the efficiency with which plants use the light provided to them, by increasing light interception and $\Phi_{\text {PSII }}$, growers can produce more edible biomass per dollar spent on electricity. Third, using lower PPFDs with longer photoperiods reduces the instantaneous heat generated by the light fixtures, thus reducing air-conditioning requirements.

This study also demonstrates that PPFD, photoperiod, and DLI effects on plants cannot be studied as individual factors. At best, one of the three factors can be held constant while the other two vary. As such, we recommend researchers always report all three parameters and consider potential interactions between these factors. 
Author Contributions: Conceptualization, S.P. and M.W.v.I.; methodology, S.P. and M.W.v.I.; formal analysis, S.P. and M.W.v.I.; investigation, S.P.; resources, M.W.v.I.; data curation, S.P. and M.W.v.I.; writing-original draft preparation, S.P.; writing-review and editing, S.P. and M.W.v.I.; visualization, S.P. and M.W.v.I.; supervision, M.W.v.I.; project administration, M.W.v.I.; funding acquisition, M.W.v.I. All authors have read and agreed to the published version of the manuscript.

Funding: This research was funded by USDA-NIFA-SCRI AWARD 2018-511-81-28365, Project LAMP.

Conflicts of Interest: The authors declare no conflict of interest. The funders had no role in the design of the study; in the collection, analyses, or interpretation of data; in the writing of the manuscript, or in the decision to publish the results.

\section{References}

1. van Iersel, M.W.; Bugbee, B. A multiple chamber, semicontinuous, crop carbon dioxide exchange system: Design, calibration, and data interpretation. J. Am. Soc. Hortic. Sci. 2000, 125, 86-92. [CrossRef] [PubMed]

2. Zelitch, I. The close relationship between net photosynthesis and crop yield. BioScience 1982, 32, 796-802. [CrossRef]

3. van Iersel, M.W.; Gianino, D. An adaptive control approach for light-emitting diode lights can reduce the energy costs of supplemental lighting in greenhouses. HortScience 2017, 52, 72-77. [CrossRef]

4. Torres, A.P.; Lopez, R.G. Measuring Daily Light Integral in a Greenhouse; Purdue Extension: West Lafayette, IN, USA, 2010; p. 7.

5. van Iersel, M.W. Optimizing LED lighting in controlled environment agriculture. In Light Emitting Diodes for Agriculture: Smart Lighting; Gupta, S.D., Ed.; Springer: Singapore, 2017; pp. 59-80. [CrossRef]

6. Weaver, G.; van Iersel, M.W. Photochemical characterization of greenhouse-grown lettuce (Lactuca sativa L. 'Green Towers') with applications for supplemental lighting control. HortScience 2019, 54, 317-322. [CrossRef]

7. Milford, G.F.J.; Lenton, J.R. Effect of photoperiod on growth of sugar beet. Ann. Bot. 1976, 40, $1309-1315$. [CrossRef]

8. Soffe, R.W.; Lenton, J.R.; Milford, G.F.J. Effects of photoperiod on some vegetable species. Ann. Appl. Biol. 1977, 85, 411-415. [CrossRef]

9. Mousseau, M. Effects of photoperiod on photosynthesis. In Advances in Photosynthesis Research; Sybesma, C., Ed.; Springer: Dordrecht, The Netherlands, 1984; pp. 305-308. [CrossRef]

10. Matsuda, R.; Ozawa, N.; Fujiwara, K. Leaf photosynthesis, plant growth, and carbohydrate accumulation of tomato under different photoperiods and diurnal temperature differences. Sci. Hortic. 2014, 170, 150-158. [CrossRef]

11. Elkins, C.; van Iersel, M.W. Longer photoperiods with the same daily light integral improve growth of Rudbeckia seedlings in a greenhouse. HortScience 2020, in press. [CrossRef]

12. Weaver, G.; van Iersel, M.W. Longer photoperiods with adaptive lighting control can improve growth of greenhouse-grown 'Little Gem' lettuce (Lactuca sativa). HortScience 2020, 55, 573-580. [CrossRef]

13. Kelly, N.; Choe, D.; Meng, Q.; Runkle, E.S. Promotion of lettuce growth under an increasing daily light integral depends on the combination of the photosynthetic photon flux density and photoperiod. Sci. Hortic. 2020, 272, 109565. [CrossRef]

14. Elkins, C.; van Iersel, M.W. Longer photoperiods with the same daily light integral increase daily electron transport through photosystem II in lettuce. Plants 2020, 9, 1172. [CrossRef] [PubMed]

15. Tucić, B.; Tomić, V.; Avramov, S.; Pemac, D. Testing the adaptive plasticity of Iris pumila leaf traits to natural light conditions using phenotypic selection analysis. Acta Oecologica 1998, 19, 473-481. [CrossRef]

16. Reinbothe, S.; Reinbothe, C. The regulation of enzymes involved in chlorophyll biosynthesis. Eur. J. Biochem. 1996, 237, 323-343. [CrossRef] [PubMed]

17. Goto, E.; Takakura, T. Prevention of lettuce tipburn by supplying air to inner leaves. Trans. ASAE 1992, 35, 641-645. [CrossRef]

18. Both, A.J. Ten Years of Hydroponic Lettuce Research; Rutgers, The State University of New Jersey: New Brunswick, NJ, USA, 2002; p. 14.

19. Zhen, S.; van Iersel, M.W. Far-red light is needed for efficient photochemistry and photosynthesis. J. Plant Physiol. 2017, 209, 115-122. [CrossRef]

20. Ruban, A.V. Evolution under the sun: Optimizing light harvesting in photosynthesis. J. Exp. Bot. 2015, 66, 7-23. [CrossRef] 
21. Bauerle, W.L.; Weston, D.J.; Bowden, J.D.; Dudley, J.B.; Toler, J.E. Leaf absorptance of photosynthetically active radiation in relation to chlorophyll meter estimates among woody plant species. Sci. Hortic. 2004, 101, 169-178. [CrossRef]

22. He, J.; Chee, C.W.; Goh, C.J. 'Photoinhibition' of Heliconia under natural tropical conditions: The importance of leaf orientation for light interception and leaf temperature. Plant Cell Environ. 1996, 19, 1238-1248. [CrossRef]

23. Massa, G.D.; Newsham, G.; Hummerick, M.E.; Caro, J.L.; Stutte, G.W.; Morrow, R.C.; Wheeler, R.M. Preliminary species and media selection for the Veggie space hardware. Gravit. Space Res. 2013, 1, 95-106.

24. Voyle, G. Cut and Come Again Vegetables; Michigan State Extension: East Lansing, MI, USA, 2014.

25. Zhu, X.-G.; Long, S.P.; Ort, D.R. Improving photosynthetic efficiency for greater yield. Annu. Rev. Plant Biol. 2010, 61, 235-261. [CrossRef]

26. Kozai, T. Resource use efficiency of closed plant production system with artificial light: Concept, estimation and application to plant factory. Proc. Jpn. Acad. Ser. B 2013, 89, 447-461. [CrossRef] [PubMed]

27. Cho, Y.Y.; Choi, K.Y.; Lee, Y.-B.; Son, J.E. Growth characteristics of sowthistle (Ixeris dentata Nakai) under different levels of light intensity, electrical conductivity of nutrient solution, and planting density in a plant factory. Hortic. Environ. Biotechnol. 2012, 53, 368-372. [CrossRef]

28. Demotes-Mainard, S.; Péron, T.; Corot, A.; Bertheloot, J.; Le Gourrierec, J.; Pelleschi-Travier, S.; Crespel, L.; Morel, P.; Huché-Thélier, L.; Boumaza, R.; et al. Plant responses to red and far-red lights, applications in horticulture. Environ. Exp. Bot. 2016, 121, 4-21. [CrossRef]

29. Kubota, C.; Chia, P.; Yang, Z.; Li, Q. Applications of far-red light emitting diodes in plant production under controlled environments. Acta Hortic. 2011, 952, 59-66. [CrossRef]

30. Park, Y.; Runkle, E.S. Far-red radiation promotes growth of seedlings by increasing leaf expansion and whole-plant net assimilation. Environ. Exp. Bot. 2017, 136, 41-49. [CrossRef]

31. Amthor, J.S. From sunlight to phytomass: On the potential efficiency of converting solar radiation to phyto-energy. New Phytol. 2010, 188, 939-959. [CrossRef]

32. Zhen, S.; van Iersel, M.W. Photochemical acclimation of three contrasting species to different light levels: Implications for optimizing supplemental lighting. J. Am. Soc. Hortic. Sci. 2017, 142, 346. [CrossRef]

33. Evans, J.R.; Clarke, V.C. The nitrogen cost of photosynthesis. J. Exp. Bot. 2018, 70, 7-15. [CrossRef]

34. Carmo-Silva, E.; Scales, J.C.; Madgwick, P.J.; Parry, M.A.J. Optimizing Rubisco and its regulation for greater resource use efficiency. Plant Cell Environ. 2014. [CrossRef]

35. Zhu, X.-G.; Long, S.P.; Ort, D.R. What is the maximum efficiency with which photosynthesis can convert solar energy into biomass? Curr. Opin. Biotechnol. 2008, 19, 153-159. [CrossRef]

36. Parry, M.A.J.; Andralojc, P.J.; Scales, J.C.; Salvucci, M.E.; Carmo-Silva, A.E.; Alonso, H.; Whitney, S.M. Rubisco activity and regulation as targets for crop improvement. J. Exp. Bot. 2013, 64, 717-730. [CrossRef]

37. van Iersel, M. Carbon use efficiency depends on growth respiration, maintenance respiration, and relative growth rate. A case study with lettuce. Plant Cell Environ. 2003, 26, 1441-1449. [CrossRef]

38. Wheeler, R.M. Carbon balance in bioregenerative life support systems: Some effects of system closure, waste management, and crop harvest index. Adv. Space Res. 2003, 31, 169-175. [CrossRef]

39. Craker, L.E.; Seibert, M.; Clifford, J.T. Growth and development of radish (Raphanus sativus, L.) under selected light environments*. Ann. Bot. 1983, 51, 59-64. [CrossRef]

40. Aikman, D.P. Potential increase in photosynthetic efficiency from the redistribution of solar radiation in a crop. J. Exp. Bot. 1989, 40, 855-864. [CrossRef]

Publisher's Note: MDPI stays neutral with regard to jurisdictional claims in published maps and institutional affiliations.

(C) 2020 by the authors. Licensee MDPI, Basel, Switzerland. This article is an open access article distributed under the terms and conditions of the Creative Commons Attribution (CC BY) license (http://creativecommons.org/licenses/by/4.0/). 